\title{
Antimicrobial Resistance Factors of Extended-Spectrum Beta-Lactamases Producing Escherichia coli and Klebsiella pneumoniae Isolated from Cattle Farms and Raw Beef in North-West Province, South Africa
}

\author{
Kotsoana Peter Montso, ${ }^{1}$ Sicelo Beauty Dlamini, ${ }^{1}$ Ajay Kumar, ${ }^{2}$ \\ and Collins Njie Ateba ${ }^{1}{ }^{1}$ \\ ${ }^{1}$ Department of Microbiology, Faculty of Natural and Agricultural Sciences, North-West University, \\ Private Bag X2046, Mmabatho 2735, South Africa \\ ${ }^{2}$ Department of Microbiology, School of Bioengineering and Biosciences, Lovely Professional University, Jalandhar-Delhi G.T. Road, \\ Phagwara, Punjab, India
}

Correspondence should be addressed to Collins Njie Ateba; collins.ateba@nwu.ac.za

Received 10 May 2019; Accepted 8 July 2019; Published 6 November 2019

Copyright (C) 2019 Kotsoana Peter Montso et al. This is an open access article distributed under the Creative Commons Attribution License, which permits unrestricted use, distribution, and reproduction in any medium, provided the original work is properly cited.

Background. Extended spectrum beta-lactamases (ESBLs) producing Enterobacteriaceae cause severe infections in humans which leads to complicated diseases. There is increasing evidence that cattle contribute to the development and spread of multidrug resistant pathogens and this raises public health concern. Despite this, data on the concurrence of ESBL producing pathogens in cattle, especially in the North-West province are rare. Therefore, the aim of the present study was to isolate, identify and characterise ESBL producing E. coli and K. pneumoniae species from cattle faeces and raw beef samples. Results. A total of 151 samples comprising 55 faeces samples and 96 raw beef samples were collected and 259 nonreplicative potential isolates of Enterobacteriaceae were obtained. One hundred and ninety-six isolates were confirmed as E. coli $(114 ; 44 \%)$ and K. pneumoniae (82; 32\%) species through amplification of $u s p A$ and $u i d A$ and $n t r A$ gene fragments, respectively. Antimicrobial susceptibility test revealed that large proportions (66.7-100\%) of the isolates were resistant to Amoxicillin, Aztreonam, Ceftazidime, Cefotaxime, and Piperacillin and were multidrug resistant isolates. Cluster analysis of antibiotic inhibition zone diameter data revealed close similarities between isolates from different sources or species thus suggested a link in antibiotic exposures. The isolates showing phenotypic resistance against ESBL antimicrobial susceptibility tests were screened for the presence of ESBL gene determinants. It was observed that $53.1 \%$ of the isolates harboured ESBL gene determinants. The blaTEM, blaSHV and blaCTX-M genes were detected in E. coli isolates $(85.5 \%, 69.6 \%$, and 58\%, respectively) while blaCTX-M and blaOXA were detected in K. pneumoniae ( $40 \%$ and $42.9 \%$, respectively). All the genetically confirmed ESBL producing E. coli and K. pneumoniae isolates were subjected to Enterobacterial Repetitive Intergenic Consensus (ERIC) PCR analysis. Fingerprinting data revealed great similarities between isolates from different areas and sources which indicates cross-contamination between cattle and beef. Conclusion. This study revealed that cattle and its associated food products, beef in particular, harbour ESBL producing pathogens. And this warrants a need to enforce hygiene measures and to develop other mitigation strategies to minimise the spread of antibiotic resistant pathogens from animals to human.

\section{Introduction}

Extended spectrum beta-lactamases (ESBL) are enzymes that can hydrolyse various $\beta$-lactam antibiotics and thus mediate resistance to penicillins, $3^{\text {rd }}$ and $4^{\text {th }}$ generation cephalosporins [1]. The genes encoding for those enzymes are commonly found both in the chromosomes and plasmids among the species belonging to Enterobacteriaceae family. As a result, ESBLs have emerged as a cause of resistance in Enterobacteriaceae, particularly E. coli and Klebsiella species. This phenomenon was first reported in 1980s in Europe and subsequently in USA [2]. Different antibiotic groups are applied at both therapeutic and subtherapeutic levels in the management of farm animals. Betalactam antibiotics are widely used in veterinary medicine 
precisely due to their high specificity, perfect selective toxicity, and potent killing effects [3,4]. Thus excessive use of these antibiotics in veterinary medicine exacerbated the emergence and dissemination of genetic determinants, particularly in E. coli and K. pneumoniae species [5].

ESBL producing E. coli and Klebsiella species cause severe infections in humans even in countries with advanced public health and health care facilities [5,6]. And most of infections are associated with cross contamination in hospital and clinic settings. Despite this, community acquired infections have also been reported in several countries worldwide $[2,7,8]$. Given that the natural hosts of E. coli and Klebsiella species are ruminants especially cattle, community acquired infections have been linked to the consumption of contaminated food particularly meat $[3,9]$. ESBL producing E. coli and Klebsiella species may be transmitted to meat if standard operating procedures as well as proper hygiene practices are not implemented in the farms and abattoirs, respectively [9-12]. Despite the public health significance of ESBL producing strains globally, and the need to assess their occurrence in food producing animals [9-11, 13], only one report has been in the Eastern Cape Province of South Africa [14].

Agriculture contributes about 2.6\% to the total GDPR and $19 \%$ to formal employment in the North-West province and it is of extreme importance to the inhabitants [15]. Despite the fact that the North-West province is known to be an important food basket in South Africa, with Maize and sunflower as the most important crops, the province is well known for cattle farming and it is sometimes referred to as the Texas of South Africa. The largest percentage of grazing land and cattle herds are seen in Stella and near Vryburg. In addition, a wide range of livestock farming, which includes cattle, sheep, goats, and chicken farming, is practiced in the Marico region. This kind of farming contributes a substantial percentage towards the economic growth of the area. Meat and dairy products are the main products produced, with commercial game ranching also contributing through the supply of meat.

The frequent use of antibiotics to enhance animal productivity provides opportunities for bacteria that harbour resistance determinants to be released into the environment through the discharge of faecal matter from animals, and this poses severe epidemiological implications on humans [16], given that the province is registered as the forth in terms of the prevalence HIV/AIDS in the country. In this paper, we report on the antimicrobial resistance profiles of ESBL producing E. coli and Klebsiella species isolated from faecal samples collected from cattle farms as well as meat from randomly selected supermarkets in the North-West province of South Africa as part of a larger study designed to use bacteriophages as biocontrol agents for multiple antibiotic resistant bacteria in the environment and the South African food chain.

\section{Materials and Methods}

2.1. Sample Collection. Sampling was done between August 2014 and May 2015. A total of 55 faeces samples were collected from 2 commercial cattle farms in Mafikeng District of the North-West province for the study. Faecal samples were collected directly from the rectum of individual animals using sterile arm-length gloves and in order to avoid duplication of sampling, the cattle were looked in their respective handling pens. In addition, 96 raw beef samples were collected from butcheries, supermarkets, and retails in 11 major cities of the four Districts of the North-West province. After collection, samples were transported on ice to the North-West University Molecular Microbiology laboratory for immediate processing. Data on antibiotic type and treatment history were collected for the purpose of understanding antibiotic exposure histories of isolates from the study population.

\subsection{Isolation and Identification of E. coli and Klebsiella} Species. Approximately, two grams ( $2 \mathrm{~g}$ ) of each meat sample was washed in $5 \mathrm{~mL}$ of $2 \%(\mathrm{w} / \mathrm{v})$ buffered peptone water (BPW) obtained from Biolab, South Africa while $2 \mathrm{~g}$ of faecal samples was dissolved in $5 \mathrm{~mL}$ of tryptic soya broth (TSB) (Merck (Pty) Ltd, South Africa). Ten-fold serial dilutions of the samples were prepared using $2 \%(\mathrm{w} / \mathrm{v})$ buffered peptone water as the diluent [7]. Aliquots of $100 \mu \mathrm{L}$ from each dilution were spread-plated on MacConkey agar (with crystal violet) (Merck (Pty) Ltd, South Africa) plates and plates were incubated aerobically at $37^{\circ} \mathrm{C}$ for 24 hours. After incubation, single pale, colourless, and pink colonies were sub-cultured onto MacConkey agar (with crystal violet) plates. One colony per plate was picked into a sterile tryptic soya broth and further incubated aerobically at $37^{\circ} \mathrm{C}$ for 24 hours for glycerol stock preparation and isolates were preserved at $-80^{\circ} \mathrm{C}$ for future use.

2.3. Preliminary Identification Tests. The pure colonies were subjected to Gram-staining [18] and the oxidase test, TSI test [19] as well as the Simmons' citrate agar test to screen for characters of E. coli and Klebsiella species.

2.4. Phenotypic Screening of Isolates for ESBL Production. All isolates were screened for ESBL production on Brilliance ESBL Agar plates [20] obtained from Oxoid, Basingstoke, United Kingdom. In order to perform this, isolates were subcultured in Brilliance ESBL Agar and plates were incubated aerobically at $37^{\circ} \mathrm{C}$ for 24 hours. ESBL-producing E. coli and Klebsiella species were identified by the presence of blue or pink and green colonies, respectively. For quality control, E. coli (ATCC 25922) and K. pneumoniae (ATCC 13883) were used as a negative control. Potential E. coli and Klebsiella isolates were further subjected to the API 20E analytical assay following the manufacturer's instructions (BioMériux, France).

2.5. Extraction of Genomic DNA. Bacteria chromosomal DNA was extracted from all presumptive isolates using Zymo Research Genomic DNA ${ }^{\mathrm{TM}}$-Tissue MiniPrep Kit following the manufacturer's instructions (Inqaba Biotechnical Industry Ltd, Pretoria, South Africa). The quality and quantity of the extracted DNA was determined using a UV-Vis Thermo Scientific $^{\mathrm{TM}}$ NanoDrop Lite Spectrophotometer (model S-22, Boeco, Germany). The DNA samples were stored at $-80^{\circ} \mathrm{C}$ for future use.

2.6. Molecular Identification of E. coli and Klebsiella Species by PCR Analysis. As an internal control all DNA samples were screened for bacterial $16 \mathrm{~S}$ rRNA gene fragments using the $27 \mathrm{~F}$ 
TABLE 1: Oligonucleotide primer sequences used for amplification of $16 \mathrm{~S}$ rRNA universal, uspA, uidA, and $n \operatorname{tr} A$ genes and PCR cycling conditions used.

\begin{tabular}{|c|c|c|c|c|c|}
\hline Primers & Sequence $\left(5^{\prime}-3^{\prime}\right)$ & $\begin{array}{l}\text { Targeted } \\
\text { gene }\end{array}$ & $\begin{array}{l}\text { Amplicon } \\
\text { size (bp) }\end{array}$ & PCR conditions and cycles & Reference \\
\hline $27 \mathrm{~F}$ & AGAGTTTGATCATGGCTCAG & \multirow[b]{2}{*}{$16 S r R N A$} & \multirow[b]{2}{*}{1420} & 1 cycle of 3 minutes at $94^{\circ} \mathrm{C}, 25$ cycles of 1 minute at & \multirow[b]{2}{*}[21]{} \\
\hline $1492 \mathrm{R}$ & GGTACCTTGTTACGACTT & & & $\begin{array}{c}94^{\circ} \mathrm{C}, 1 \text { minute at } 55^{\circ} \mathrm{C}, 2 \text { minutes at } 72^{\circ} \mathrm{C} ; 1 \text { cycle of } \\
10 \text { minutes at } 72^{\circ} \mathrm{C}\end{array}$ & \\
\hline uspAF & CCGATACGCTGCCAATCAGT & \multirow[b]{2}{*}{ uspA } & \multirow[b]{2}{*}{884} & 1 cycle of 5 minutes at $95^{\circ} \mathrm{C}, 30$ cycles of 30 seconds at & \multirow[b]{2}{*}[22]{} \\
\hline uspAR & ACGCAGACCGTAGGCCAGAT & & & $\begin{array}{c}94^{\circ} \mathrm{C}, 30 \text { seconds at } 56^{\circ} \mathrm{C}, 30 \text { seconds at } 72^{\circ} \mathrm{C} ; 1 \text { cycle of } \\
5 \text { minutes at } 72^{\circ} \mathrm{C}\end{array}$ & \\
\hline uidAF & CTGGTATCAGCGCGAAGTCT & \multirow[b]{2}{*}{ uidA } & \multirow[b]{2}{*}{556} & 1 cycle of 10 minutes at $95^{\circ} \mathrm{C}, 35$ cycles of 45 seconds at & \multirow{4}{*}[23]{} \\
\hline uidAR & AGCGGGTAGATATCACACTC & & & $\begin{array}{c}95^{\circ} \mathrm{C}, 30 \text { seconds at } 59^{\circ} \mathrm{C}, 1 \text { minute } 30 \text { seconds at } 72^{\circ} \mathrm{C} ; 1 \\
\text { cycle of } 10 \text { minutes at } 72^{\circ} \mathrm{C}\end{array}$ & \\
\hline$n \operatorname{tr} A$ & CATCTCGATCTGCTGGCCAA & \multirow[b]{2}{*}{$n t r A$} & \multirow[b]{2}{*}{90} & 1 cycle of 10 minutes at $95^{\circ} \mathrm{C}, 35$ cycles of 45 seconds at & \\
\hline$n t r A$ & GCGCGGATCCAGCGATTGGA & & & $\begin{array}{c}95^{\circ} \mathrm{C}, 30 \text { seconds at } 55^{\circ} \mathrm{C}, 1 \text { minute } 30 \text { seconds at } 72^{\circ} \mathrm{C} ; 1 \\
\text { cycle of } 10 \text { minutes at } 72^{\circ} \mathrm{C}\end{array}$ & \\
\hline
\end{tabular}

and 1492R universal oligonucleotide primer sequences [21] and were synthesised by Inqaba Biotechnical Industries, [PTY] Ltd, South Africa), and are shown in Table 1.

\subsection{E. coli and Klebsiella pneumoniae Species Specific PCR} Identification Tests. Amplification of the uidA and uspA housekeeping genes specific to $E$. coli species and $n t r A$ gene fragments related to $K$. pneumoniae specific sequences was performed following previous protocols [22, 23], with minor modifications. PCR reaction mixtures were prepared as standard $25 \mu \mathrm{L}$ volumes that constituted $12.5 \mu \mathrm{L}$ of $2 \mathrm{X}$ DreamTaq Green Master Mix, $11 \mu \mathrm{L}$ RNase free PCR water, $0.5 \mu \mathrm{L}$ mixture of the forward and reverse primers $(0.25 \mu \mathrm{L}$ of each primer) and $1 \mu \mathrm{L}$ of template DNA. All the PCR reagents were Fermentas USA products supplied by Inqaba Biotechnical Industry Ltd, Sunnyside, South Africa. Amplifications were performed using DNA thermal cycler (model-Bio-Rad C1000 Touch TM Thermal Cycler) obtained from Bio-Rad Laboratories, Inc. USA, oligonucleotide primer sequences synthesised by Inqaba Biotechnical Industries (Pty) Ltd, Pretoria, South Africa and conditions that appear in Table 1 . PCR amplicons were stored at $4^{\circ} \mathrm{C}$ until electrophoresis.

2.8. Sequencing of PCR Amplicons. Bacterial 16S rRNA gene fragments were sequenced by Inqaba Biotechnical Industries (Pty) Ltd, Pretoria, South Africa and sequences were subjected to a Blast Search Tool (http://blast.ncbi.nlm.nmih.gov/Blast. $\mathrm{cg}$ ) in order to confirm the identities of the isolates.

2.9. Antimicrobial Susceptibility Test. An in-vitro antimicrobial susceptibility test was performed on all isolates according to the Kirby-Bauer disk-diffusion method [24] in order to determine antibiotic resistant profiles and making use of antibiotic discs (Mast Diagnostics, Merseyside, UK) which were placed on inoculated Muller Hinton agar (MHA) plates. The following antibiotic impregnated discs were used: Amoxicillin $(10 \mu \mathrm{g})$, Piperacillin $(100 \mu \mathrm{g})$, Cephalothin $(30 \mu \mathrm{g})$, Cefotaxime $(30 \mu \mathrm{g})$, Ceftazidime $(30 \mu \mathrm{g})$, Cefepime $(30 \mu \mathrm{g})$, Cefoxitin $(30 \mu \mathrm{g})$, Aztreonam $(30 \mu \mathrm{g})$, and Ertapenem $(10 \mu \mathrm{g})$, and these antibiotic discs contained the CLSI approved concentrations
[25]. Antibiotic growth inhibition zone diameter data were compared with standard reference values in order to classify the isolates as sensitive, intermediate resistance or resistant to a particular antibiotic [25]. In the evaluation of the results, strains displaying intermediate resistance were regarded as resistant. E. coli ATCC 25922 and K. pneumoniae ATCC 13883 strains were used as positive controls.

2.10. Detection of ESBL Genes in E. coli and Klebsiella Species by Multiplex PCR Analysis. All confirmed E. coli and Klebsiella isolates were screened for the presence of the blaCTX-M, blaOXA, blaSHV, blaTEM, blaCMY, blaCMY-1, and blaCMY-2 ESBL producing genes determinants using previously described PCR protocol [26, 27]. The primer sequences, targeted genes, amplicon sizes, and PCR conditions are listed in Table 2 . The reactions were prepared in standard $25 \mu \mathrm{L}$ reaction volumes that comprised $12.5 \mu \mathrm{L}$ of a $2 X$ DreamTaq Green Master Mix, $11 \mu \mathrm{L}$ nuclease free water, $0.25 \mu \mathrm{L}$ set of each primer, and $1 \mu \mathrm{L}$ of template DNA. All the PCR reagents were Fermentas USA products supplied by Inqaba Biotechnical Industry Ltd, Sunnyside, South Africa. The amplifications were performed using DNA thermal cycler (model-Bio-Rad C1000 Touch TM Thermal Cycler) obtained from Bio-Rad Laboratories, Inc. USA and cycling conditions indicated in Table 2. PCR amplicons were held at $4^{\circ} \mathrm{C}$ until resolved by electrophoresis.

2.11. ERIC-PCR Genetic Typing of ESBL Producing E. coli and $K$. pneumoniae Isolates. All ESBL producing E. coli and $K$. pneumoniae isolates were subjected to ERIC-PCR in order to determine the genetic similarities between the isolates. ERIC-PCR was performed using a single oligonucleotide primer ERIC2 (5'-AAGTAAGTGACTGGGGTGAGCG-3') as previously described [28]. The ERIC fingerprints were compared and analysed for the presence, absence, and intensity of band data obtained.

2.12. Electrophoresis of PCR Products. PCR products were separated by electrophoresis on a $2 \%(\mathrm{w} / \mathrm{v})$ agarose gel containing ethidium bromide $(0.1 \mu \mathrm{g} / \mathrm{mL}$ ) (Sambrook et al., 1989). Depending on the size of the amplicons, a $1 \mathrm{~Kb}$ 
TABLE 2: Oligonucleotide primer sequences used for detection of ESBL genes and PCR cycling conditions used.

\begin{tabular}{|c|c|c|c|c|c|}
\hline Primer & Primer sequence $\left(5^{\prime}-3^{\prime}\right)$ & Target gene & Amplicons size (bp) & PCR conditions and cycles & Reference \\
\hline blaTEMF & AAACGCTGGTGAAAGTA & hlaTFM & 822 & \multirow{8}{*}{$\begin{array}{c}1 \text { cycle of } 5 \text { minutes at } 94^{\circ} \mathrm{C}, 35 \\
\text { cycles of } 30 \text { seconds at } 94^{\circ} \mathrm{C}, \\
1 \text { minute at } 45^{\circ} \mathrm{C}, 1 \text { minute at } \\
72^{\circ} \mathrm{C} ; 1 \text { cycle of } 10 \text { minutes at } \\
72^{\circ} \mathrm{C}\end{array}$} & \multirow{8}{*}[27]{} \\
\hline blaTEMR & AGCGATCTGTCTAT & bia IEM & 822 & & \\
\hline blaSHVF & ATGCGTTATATTCGCCTGTG & hlasHV & 753 & & \\
\hline blaSHVR & TGCTTTGTTATTCGGGCCAA & 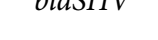 & 153 & & \\
\hline blaCTX-MF & CGCTTTGCGATGTGCAG & hlo $C T Y-M$ & 550 & & \\
\hline blaCTX-MR & ACCGCGATATCGTTGGT & $\operatorname{ogac} 1 \Lambda-N$ & 500 & & \\
\hline blaOXAF & ATATCTCTACTGTTGCATCTCC & \multirow{2}{*}{ blaOXA } & \multirow{2}{*}{619} & & \\
\hline blaOXAR & АААСССТТСАААССАТСС & & & & \\
\hline blaCMY-1F & GTGGTGGATGCCAGCATCC & blaCMY-1 & 015 & \multirow{4}{*}{$\begin{array}{c}1 \text { cycle of } 3 \text { minutes at } 94^{\circ} \mathrm{C} \text {, } \\
25 \text { cycles of } 1 \text { minute at } 94^{\circ} \mathrm{C} \text {, } \\
1 \text { minute at } 58^{\circ} \mathrm{C}, 1 \text { minute at } \\
72^{\circ} \mathrm{C} ; 1 \text { cycle of } 10 \text { minutes at } \\
72^{\circ} \mathrm{C}\end{array}$} & \multirow{4}{*}{ [26] } \\
\hline blaCMY-1R & GGTCGAGCCGGTCTTGTTGAA & & 915 & & \\
\hline blaCMY-2F & GCACTTAGCCACCTATACGGCAG & & & & \\
\hline blaCMY-2R & GCTTTTCAAGAATGCGCCAGG & blaCM & 758 & & \\
\hline
\end{tabular}

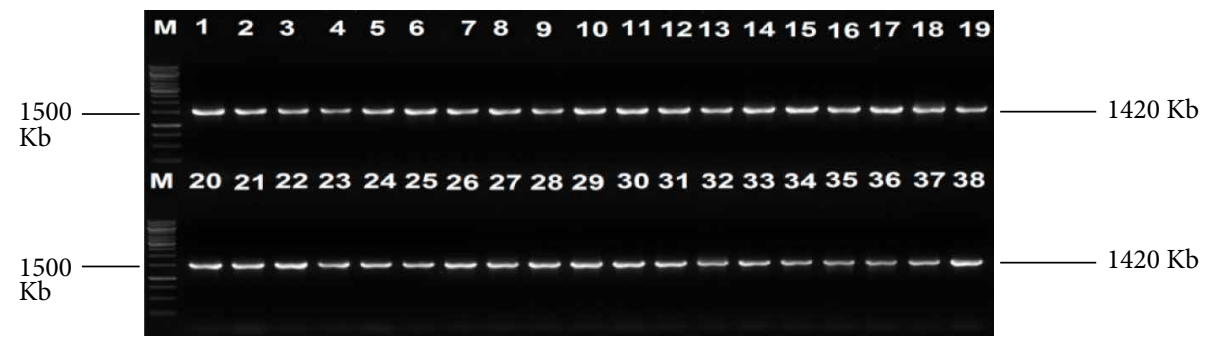

FIGURE 1: A 2\% (w/v) agarose gel of $16 \mathrm{~S}$ rRNA gene fragments amplified from E. coli and Klebsiella isolates as well as E. coli (ATCC 25922) and K. pneumoniae (ATCC 13883) control strains. Lane $\mathrm{M}=$ DNA marker (1 kb O'GeneRuler DNA marker), Lane $1=E$. coli (ATCC 25922), Lane $2=K$. pneumoniae (ATCC 13883), Lanes 3-19=16S rRNA gene fragments of E. coli isolates from cattle faeces and beef samples, Lanes 20-38 = 16S rRNA gene fragments of K. pneumoniae isolates from cattle faeces and beef samples.

or 100 bp DNA molecular weight marker (Fermentas, USA) was included in each gel. Electrophoresis was conducted in a horizontal Pharmacia biotech equipment system (model Hoefer HE 99X, Amersham Pharmacia biotech, Sweden) for 1 hour at $80 \mathrm{~V}$ using $1 \mathrm{X}(\mathrm{v} / \mathrm{v})$ TAE buffer. A ChemiDoc Imaging System (Bio-RAD ChemiDocTM MP Imaging System, UK) was used to capture the image using Gene Snap (version 6.00.22) software (GSL Biotech Chicago, USA).

2.13. Statistical Analysis. Statistical analysis of antibiotic resistance data was performed using the Minitab Release software (version 13.31) produced by Minitab, LLC, Pennsylvania, USA. Correlations between antibiotic resistant isolates from the various sources were determined using the percentage antibiotic resistance for each antibiotic the Pearson's product of moment and scored as significant if $p \leq 0.05$. Furthermore, cluster analysis of isolates from the different stations was determined using bacterial growth inhibition zone diameter data obtained from antibiotic susceptibility tests on Statistica version 12 (Statsoft, US). Analysis was performed using Wards algorithm and Euclidean distances [34].

\section{Results}

3.1. Detection of E. coli and Klebsiella pneumoniae Isolated from Faecal and Beef Samples. One hundred and fifty-one
( 55 cattle faeces and 96 raw beef) samples were collected and analysed. A total of 259 nonreplicative presumptive isolates were selected based on differences in colonial morphologies. All the isolates were Gram-negative rod shaped bacteria that were oxidase positive and hydrolysed the substrates glucose, sucrose and lactose at sample concentrations of $0.1,1.0$, and $1.0 \%$, respectively in the TSI medium. Out of 259 isolates that were subjected to API 20E assay, 145 (56\%) E. coli and 114 (44\%) Klebsiella species were positively identified. Large proportions 196 (76.4\%) of these isolates were confirmed as ESBL producing strains based on activity on Brilliance ESBL agar and this comprised 114 (58.2\%) E. coli (blue colonies) and 82 (41.8\%) Klebsiella species (green colonies). As an internal control the $16 \mathrm{~S}$ rRNA gene fragment was successfully amplified in all the 259 isolates and Figure 1 indicates a $\%(\mathrm{w} / \mathrm{v})$ agarose gel image of the bacterial 16S rRNA gene fragments. Large proportions $44 \%$ of these isolates were confirmed as E. coli, while $32 \%$ were positive for Klebsiellapneumoniae through amplification of uidA and $u s p A$ and $n t r A$ gene fragments, respectively. Figures 2-4 indicate $2 \%$ agarose gel images of the uidA, usp $A$ and $n t r A$ gene fragments amplified in the study. A total of 63 (24.3\%) isolates that were negative for E. coli and Klebsiella pneumoniae specific sequences were classified as others (Figure 5).

3.2. 16S rRNA Gene Sequencing. The 16S rRNA gene sequence data indicated that $E$. coli isolates possessed great ( $97 \%$ to 


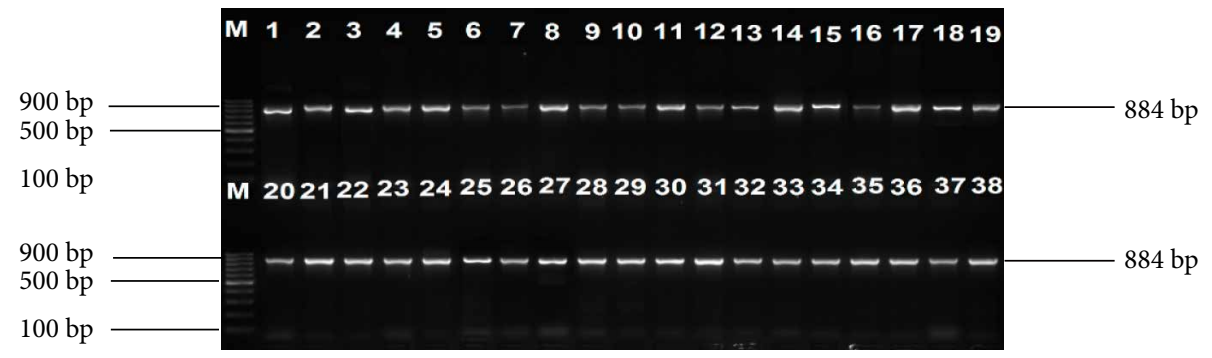

FIGURE 2: A 2\% (w/v) agarose gel image showing the uspA gene fragments amplified from all E. coli isolates and E. coli (ATCC 25922) control strain. Lane $\mathrm{M}=100 \mathrm{bp}$ DNA Ladder, Lane $1=u s p A$ gene fragments amplified from E. coli (ATCC 25922) control strain, Lanes 2-38=uspA gene fragments amplified from $E$. coli isolates from cattle faeces and beef samples.

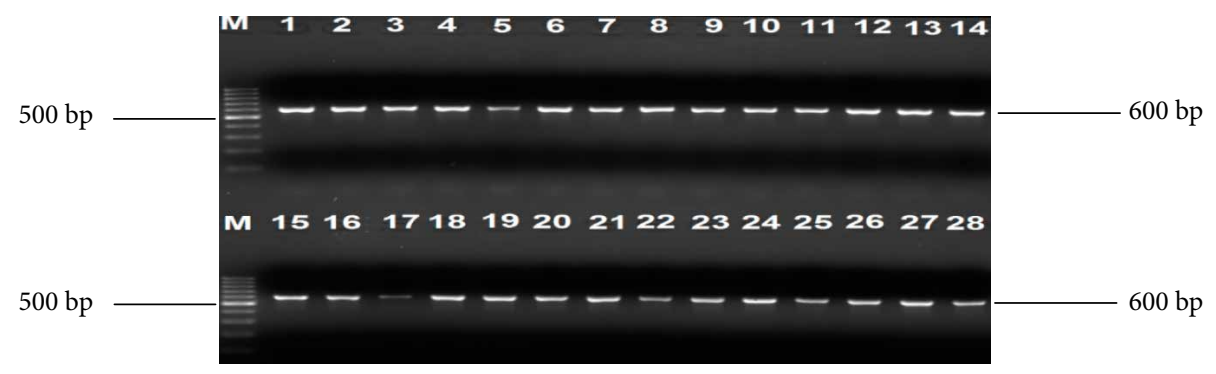

FIGURE 3: A 2\% (w/v) agarose gel image showing uidA gene fragments amplified from all E. coli isolates and E. coli (ATCC 25922) control strain. Lane $\mathrm{M}=100$ bp DNA Ladder, Lane $1=$ uidA gene fragments amplified from E. coli (ATCC 25922) control strain, Lanes 2-28=uidA gene fragments amplified from $E$. coli isolates from cattle faeces and beef samples.

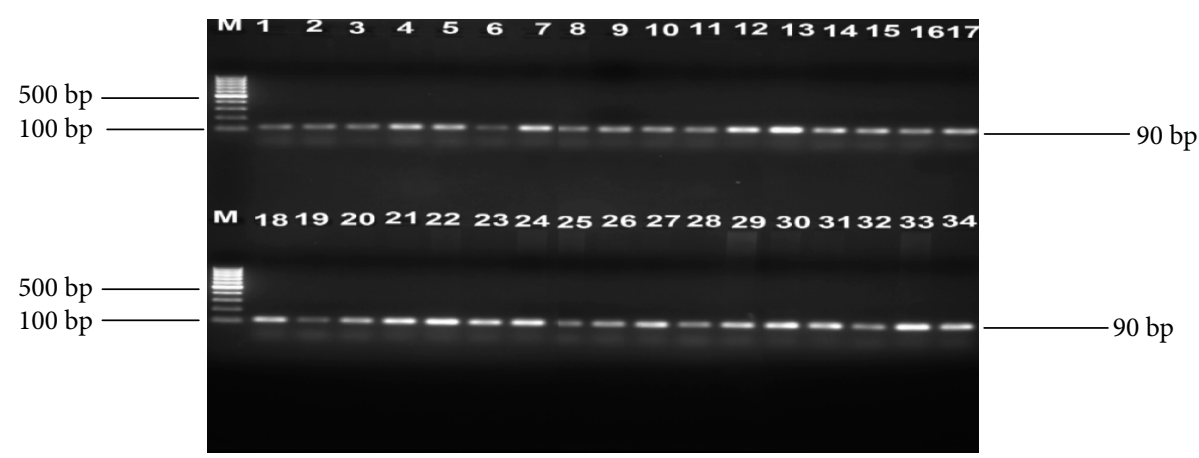

Figure 4: A 2\% (w/v) agarose gel image showing ntrA gene fragments amplified from all K. pneumoniae isolates and K. pneumoniae (ATCC 13883) control strain. Lane $\mathrm{M}=100 \mathrm{bp}$ DNA Ladder, Lane $1=n t r A$ gene fragments amplified from K. pneumoniae (ATCC 13883) control strain and Lanes 2-34=ntrA gene fragments amplified from $K$. pneumoniae isolates from cattle faeces and beef samples.

99\%) similarities to E. coli strain O157:H6 (Accession No: CP007592.1), E. coli strain C15 (Accession No: CP011018.1) and E. coli strain SUS3EC (Accession No: KF991476.1) $16 \mathrm{~S}$ ribosomal RNA gene, partial sequence. In addition, $K$. pneumoniae isolates possessed 95\% sequence similarities to K. pneumoniae strain QLR-1 (Accession No: KM096433.1) and a K. pneumoniae strain (Accession No: HG416956.1) 16S ribosomal RNA gene, partial sequence.

3.3. Antibiotic Susceptibility Profiles of Isolates. A total of 196 PCR confirmed E. coli and Klebsiellapneumoniae isolates that revealed ESBL traits on Brilliance ESBL agar were subjected to antimicrobial susceptibility test in order to evaluate their resistance patterns. The number of isolates that was resistant to the different antimicrobial agents was translated into percentages in Table 3. Large proportions (85-100\%) of the isolates from all the sampling sites except for those from samples from Mafikeng (54.5\%) and Boshoek (66.7\%) were resistant to Ampicillin. In addition, significant proportions (66.7-100\%) of the isolates from Stella and Boshoek were resistant to Cefotaxime, Piperacillin, Ceftazidime, and Aztreonam. Similarly, large proportions (90\%) of the isolates from Potchefstroom were resistant to Amoxicillin, Cephalothin, and Piperacillin. Despite the fact that some isolates obtained in the study displayed low levels of resistance to some of the antibiotics tested, the detection of multi-drug resistant isolates was a cause for concern since they may pose severe health complications on humans. 


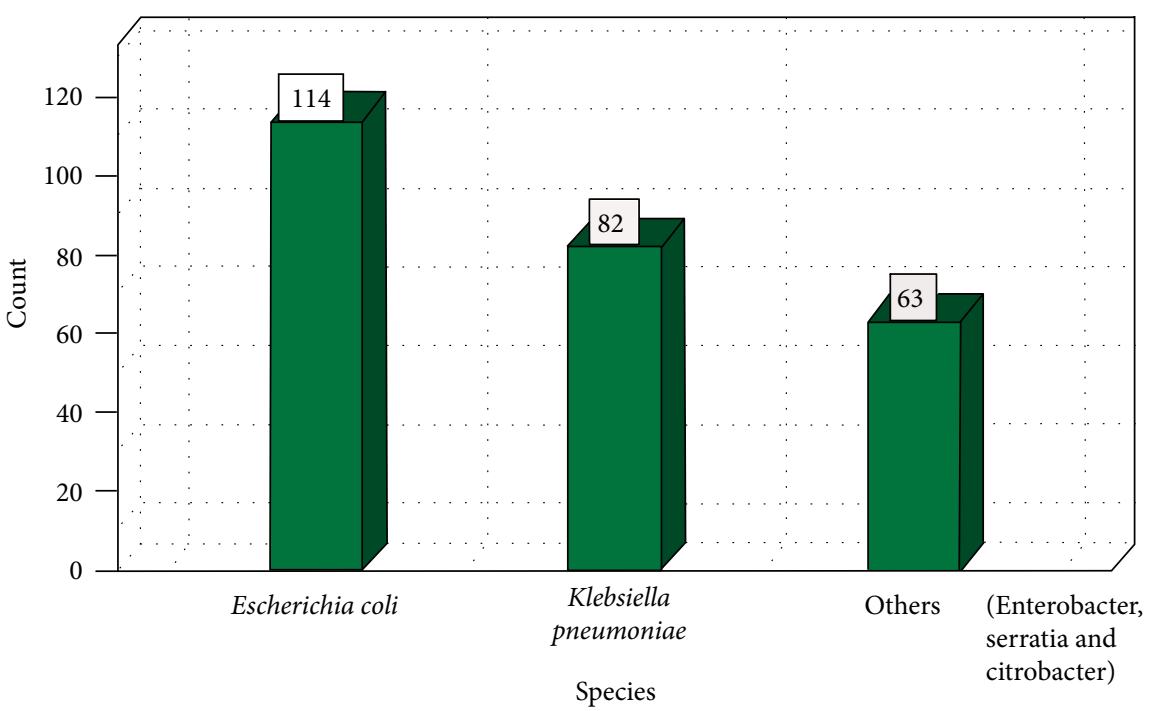

Figure 5: Distribution of E. coli and K. pneumoniae isolated from beef and faeces samples based on genus specific PCR analysis.

TABle 3: Percentage antibiotic resistance pattern of the isolates from cattle faeces and beef samples.

\begin{tabular}{|c|c|c|c|c|c|c|c|c|c|}
\hline \multirow{2}{*}{ Area } & \multicolumn{9}{|c|}{ Antibiotics resistance (\%) } \\
\hline & FOX & CTX & KF & ETP & $\mathrm{CPM}$ & PRL & CAZ & ATM & A \\
\hline Boshoek & 33.3 & 100 & 66.7 & 33.3 & 33.3 & 66.7 & 66.7 & 66.7 & 66.7 \\
\hline Brits & 16.7 & 50 & 16.7 & 33.3 & 33.3 & 33.3 & 16.7 & 16.7 & 100 \\
\hline Carletonville & 16.7 & 66.7 & 33.3 & 33.3 & 33.3 & 50 & 16.7 & 50 & 100 \\
\hline Lichtenburg & 28.6 & 14.3 & 57.1 & 14.3 & 14.3 & 42.9 & 28.6 & 14.3 & 85.7 \\
\hline Mafikeng & 12.1 & 43.4 & 30.3 & 17.2 & 15.2 & 37.4 & 17.2 & 23.2 & 54.5 \\
\hline Marikana & 11.1 & 55.6 & 66.7 & 33.3 & 55.6 & 88.9 & 33.3 & 44.4 & 100 \\
\hline Potchefstroom & 10 & 50 & 90 & 30 & 30 & 90 & 40 & 50 & 90 \\
\hline Rustenburg & 28 & 52 & 60 & 28 & 32 & 60 & 28 & 36 & 96 \\
\hline Stella & 33.3 & 100 & 33.3 & 33.3 & 33.3 & 100 & 66.7 & 66.7 & 100 \\
\hline Ventersdorp & 14.3 & 42.9 & 42.9 & 14.3 & 28.6 & 57.1 & 14.3 & 42.9 & 100 \\
\hline Vryburg & 10 & 70 & 65 & 15 & 35 & 70 & 30 & 45 & 85 \\
\hline
\end{tabular}

FOX $=$ Cefoxitin, $\mathrm{CTX}=$ Cefotaxime, $\mathrm{KF}=$ Cephalothin, $\mathrm{ETP}=$ Ertapenem, $\mathrm{CPM}=$ Cefepime, $\mathrm{PRL}=$ Piperacillin, CAZ=Ceftazidime, $\mathrm{ATM}=\mathrm{Aztreonam}$, A = Amoxicillin.

\subsection{Cluster Analysis of E. coli and Klebsiella pneumoniae Species} for Antibiotic Resistance Relationship. A total of 77 multi-drug resistant isolates that comprised 40 E. coli and 37 Klebsiella pneumoniae were randomly selected from all sampling locations and subjected to cluster analysis using their antibiotic growth inhibition zone diameter data. Random selection was due to the fact that the software can only accommodate a maximum of 77 isolates. A total of 52 isolates formed reliable cluster patterns and two main clusters (Cluster 1 and Cluster 2) were identified (Figure 6). The largest cluster (Cluster 1) contained 43 isolates and it was divided into two subclusters (Cluster $1 \mathrm{~A}=39$ ) and (Cluster $1 \mathrm{~B}=9$ ). The clusters were analysed for patterns of association of isolates from different sources and/or locations and data are presented in Table 4.

Subcluster 1A was considered a mixed cluster since it contained isolates from all the 11 sampling sites and large proportions $(28.2 \%$ and $20.5 \%)$ of these isolates were obtained from beef and cattle faeces samples, respectively. On the contrary, subcluster 1B as well as cluster 2 did not contain any of the isolates obtained from cattle faeces in the study. In addition, a significant proportion (33.3\%) of the isolates from samples collected in Mafikeng were dominant in cluster 2 as well as small proportions (11.1\%) of isolates from the other six (6) sampling sites. Subcluster $1 \mathrm{~B}$ comprised $25 \%$ and $50 \%$ of the isolates from Brits and Mafikeng, respectively. The great similarities in the antimicrobial resistant profiles of the isolates from different sampling sites clearly indicate similarities in antibiotic exposure histories.

3.5. Molecular Detection of ESBL Determinant Genes in E. coli and K. pneumoniae Isolates. All 196 isolates that comprised $114 \mathrm{E}$. coli and $82 \mathrm{~K}$. pneumoniae were screened by multiplex PCR analysis for ESBL gene determinants (blaTEM, blaSHV, blaCTX-M, blaOXA, and blaCMY-2). The proportion of isolates that were positive for the respective genes are shown in Table 5, while Figures 7 and 8 indicate a 2\% (w/v) gel 
TABle 4: Percentage representation of E. coli and K. pneumoniae isolated from various areas and/or sources within different clusters.

\begin{tabular}{|c|c|c|c|c|}
\hline Sampling area & Source & Cluster $1 \mathrm{~A} N=39$ & Cluster $1 \mathrm{~B} N=4$ & $\begin{array}{c}\text { Cluster } \\
2 \mathrm{~A} N=9\end{array}$ \\
\hline Brits & Beef & $2(5.1 \%)$ & $1(25 \%)$ & $1(11.1 \%)$ \\
\hline Boshoek & Beef & $1(2.6 \%)$ & $0(0 \%)$ & $1(11.1 \%)$ \\
\hline Carletonville & Beef & $5(12.8 \%)$ & $0(0 \%)$ & $0(0 \%)$ \\
\hline Lichtenburg & Beef & $2(5.1 \%)$ & $0(0 \%)$ & $0(0 \%)$ \\
\hline \multirow{2}{*}{ Mafikeng } & Beef & $11(28.2 \%)$ & $2(50 \%)$ & $3(33.3 \%)$ \\
\hline & Cattle faeces & $8(20.5 \%)$ & $0(0 \%)$ & $0(0 \%)$ \\
\hline Marikana & Beef & $0(0 \%)$ & $0(0 \%)$ & $0(0 \%)$ \\
\hline Potchefstroom & Beef & $2(2.6 \%)$ & $0(0 \%)$ & $1(11.1 \%)$ \\
\hline Rustenburg & Beef & $4(10.3 \%)$ & $1(25 \%)$ & $1(11.1 \%)$ \\
\hline Stella & Beef & $1(2.6 \%)$ & $0(0 \%)$ & $1(11.1 \%)$ \\
\hline Ventersdorp & Beef & $2(2.3 \%)$ & $0(0 \%)$ & $1(11.1 \%)$ \\
\hline Vryburg & Beef & $1(2.3 \%)$ & $0(0 \%)$ & $0(0 \%)$ \\
\hline
\end{tabular}

TABLE 5: Proportion of ESBLs genes detected from isolates obtained from cattle faeces and raw beef samples.

\begin{tabular}{|c|c|c|c|c|c|c|c|}
\hline \multirow{2}{*}{ Bacteria species } & \multirow{2}{*}{$\begin{array}{l}\text { No of isolates positive for ESBL } \\
\text { activity }\end{array}$} & \multicolumn{6}{|c|}{ No. of isolates positive for ESBL associated genes } \\
\hline & & $b l a_{T E M}$ & $b l a_{S H V}$ & $b l a_{C T X-M}$ & $b l a_{O X A}$ & $b l a_{C M Y-1}$ & $b l a_{C M Y-2}$ \\
\hline E. coli & $69(66.3 \%)$ & $59(85.5 \%)$ & $48(69.6 \%)$ & $40(58 \%)$ & $20(29 \%)$ & $0(0 \%)$ & $7(10.1 \%)$ \\
\hline K. pneumoniae & $35(33.7 \%)$ & $8(22.9 \%)$ & $12(34.3 \%)$ & $14(40 \%)$ & $15(42.9 \%)$ & $0(0 \%)$ & $0(0 \%)$ \\
\hline Total & $104(100 \%)$ & $67(64.4 \%)$ & $60(57.7 \%)$ & $54(51.9 \%)$ & $35(33.7 \%)$ & $0(0 \%)$ & $7(6.7 \%)$ \\
\hline
\end{tabular}

image of the blaTEM (1100bp), blaSHV (740 bp), blaCTX-M (550 bp) and blaOXA (470 bp). Large proportions $53.1 \%$ of the isolates harboured the ESBL genes targeted in the study. In addition, ESBL gene determinants were frequently detected in E. coli (35\%) isolates than in K. pneumoniae (18\%) (Table 5). Moreover, all ESBL genes investigated were detected among the E. coli isolates and this blaTEM gene fragment was dominant $(85.5 \%)$. Despite the fact the blaTEM gene was detected in $64.4 \%$ isolates, only a small proportion $(22.8 \%)$ of $K$. pneumoniae isolates harboured this gene.

The blaSHV and blaCTX-M were detected at proportions of $57.7 \%$ and $51.9 \%$, respectively, among the E. coli and $K$. pneumoniae isolates. The blaSHV gene was dominant (69.6\%) among E. coli species when compared to K. pneumonia (34.3\%) isolates. Similarly, a larger proportion (58\%) of $E$. coli isolates harboured the blaCTX-M gene than K. pneumonia (40\%) isolates. As depicted in Figure 9, the blaCMY-2 gene determinant was the least detected among all the ESBL genes targeted and was harboured by only 7 (10\%) E. coli isolates while none of the K. pneumoniae isolates was positive for this gene.

3.6. Genotypic Typing of ESBL Producing E. coli and Klebsiella pneumoniae Isolated from Faecal and Beef Samples. The genetic relatedness of 196 (114 E. coli and 82 K. pneumoniae) isolates was determined by subjecting them to ERIC PCR analysis. Results indicated great genetic similarities among isolates and fingerprinting patterns of $E$. coli isolates possessed 4 to 9 bands per isolate ranging between $0.25 \mathrm{~kb}$ and $10 \mathrm{~kb}$ (Figure 10). However, a large proportion of the E. coli isolates had fingerprints characterised by 6 bands per isolate. K. pneumoniae, produced genetic fingerprinting patterns that were characterised by $2-8$ bands per isolate ranging from $0.25 \mathrm{~kb}$ to over $10 \mathrm{~kb}$ (Figure 11). Similarly, large proportions of the K. pneumoniae isolates produced six bands per isolate. The great genetic relatedness among $K$. pneumoniae and $E$. coli isolates detected in samples obtained from different sample sites coupled with the fact that they were recovered from both cattle and raw beef samples indicates some form of cross contamination in the food chain particularly in abattoirs, but does not exclude contamination during handling and packaging of meat. This also indicates the need to improve farm management practices in the area.

\section{Discussions}

Food-producing animals are known to be reservoirs for ESBLproducing strains, especially $E$. coli $[9,14,29,30]$. Animals colonised with ESBL producing strains have been reported to serve as potential sources of E. coli and Klebsiella pneumoniae infections in humans particularly in rural communities [31] and this was a course for concern. The primary objective of the present study was to isolate and identify $E$. coli and Klebsiella pneumoniae isolates from cattle faeces and beef samples. In the present E. coli and Klebsiella pneumoniae species were successfully isolated and confirmed using biochemical tests, genus specific PCR analysis and 16S rRNA gene sequencing. The use of uidA and uspA and ntrA housekeeping genes to confirm the identities of $E$. coli and Klebsiella pneumoniae species, respectively have been applied in other studies $[22,23]$. In our study, E. coli was dominant among isolates recovered from cattle faeces and raw beef samples when compared to Klebsiella pneumoniae. Similar observations have 


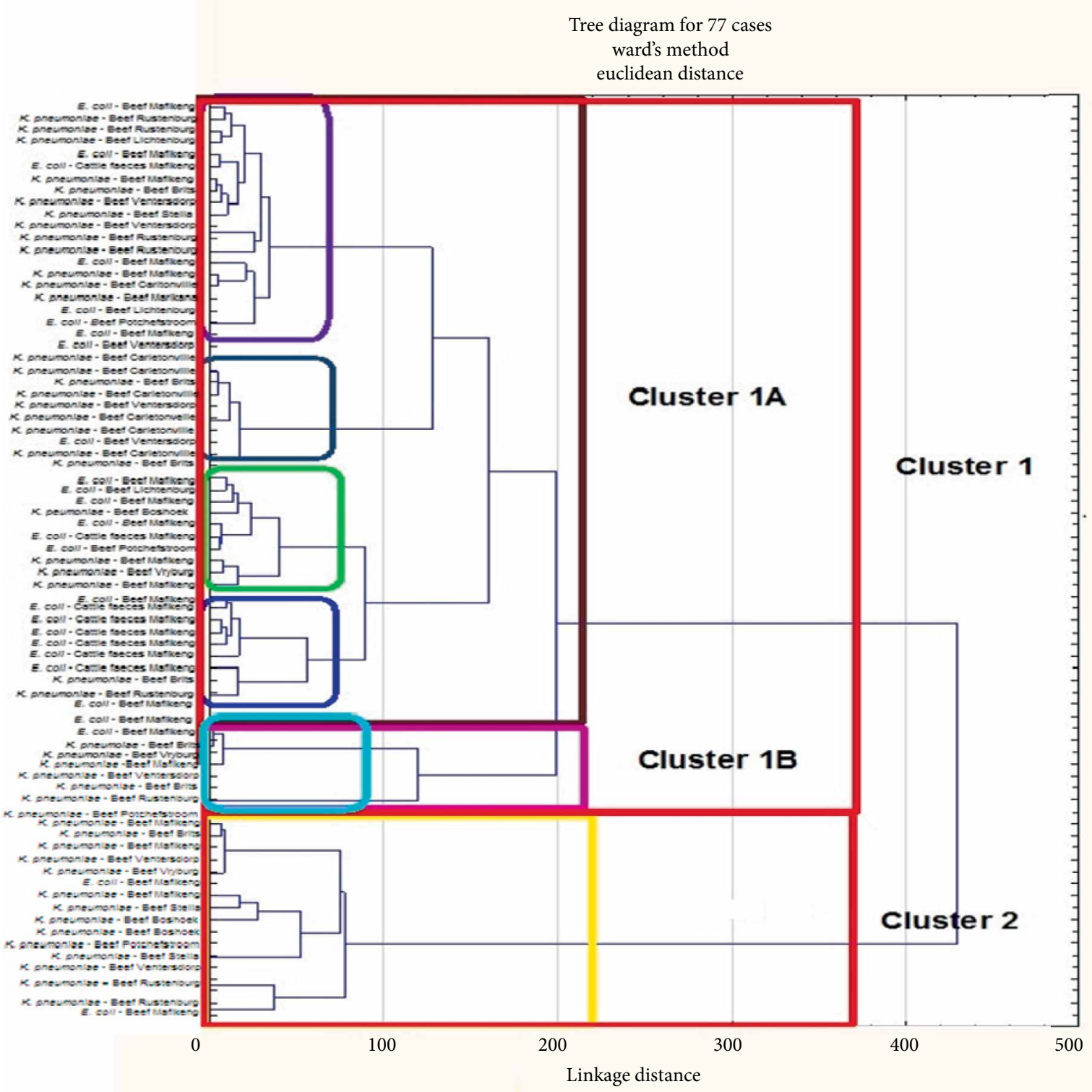

FIGURE 6: Dendrogram showing the relationship between isolates from cattle faeces and raw beef samples based on antimicrobial inhibition zone diameter data.

been reported $[11,12,23]$ and these findings are in agreement with the generalisation that $E$. coli are highly prevalent in the gastrointestinal track of ruminants when compared to other members of the family Enterobacteriaceae [23]. This also explains why E. coli species are approved for use in contamination source tracking investigations.

Another objective of the study was to determine the proportion of E. coli and Klebsiella pneumoniae isolates that possessed ESBL resistant phenotypes as well as their resistant determinants. This was motivated by the fact that ESBLproducing E. coli and Klebsiella pneumoniae have been frequently found to produce extended-spectrum $\beta$-lactamases (ESBLs) and thus making them resistant to cephalosporin antibiotics, as well as a number of other classes of antibiotics [6]. In addition, infections caused by ESBL-producing pathogens are problematic due to the potential of harbouring coresistant determinants to other antimicrobial agents hence present severe challenge to public health practitioners resulting from limited antibiotic treatment options. In general, a large proportion 196 (76.4\%) of these isolates tested in the study produced phenotypic ESBL activities on Brilliance ESBL agar. These results are in accordance with previous findings [10, 11, 14, 32, 33]. Although the results from these studies varied significantly, it has also been observed that the occurrence of pathogenic $E$. coli strains was higher in cattle faeces than in beef samples [17]. This was not surprising since $E$. coli strains are known occur as a normal flora of ruminants, especially cattle [12]. However, the most susceptible host in a given area cannot be assumed without thorough analysis since data from our previous findings revealed that pigs rather than cattle are the principal host 


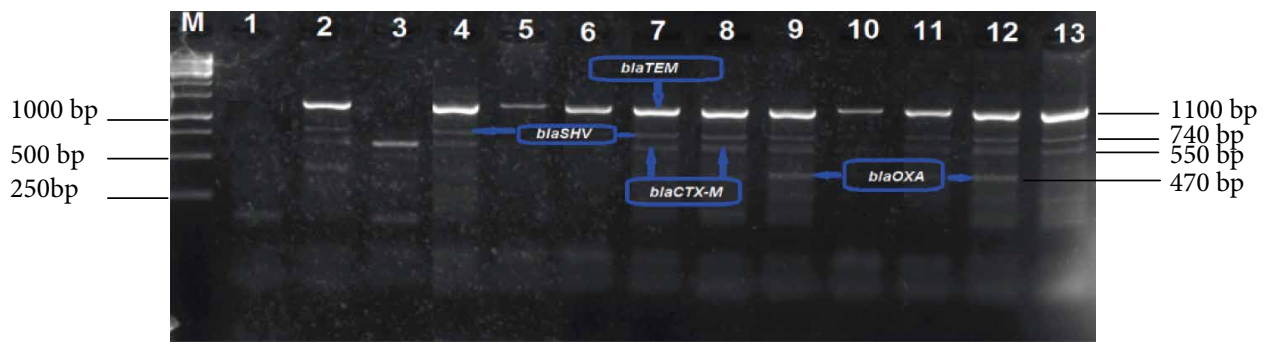

Figure 7: A $2 \%(\mathrm{w} / \mathrm{v})$ agarose gel image showing ESBL $\left[b l a_{T E M}(1100 \mathrm{bp}), b l a_{S H V}(740 \mathrm{bp}), b l a_{C T X-M}(550 \mathrm{bp})\right.$ and $\left.b l a_{O X A}(470 \mathrm{bp})\right]$ gene fragments amplified from $E$. coli isolates. Lane $\mathrm{M}=1 \mathrm{~kb}$ DNA marker, Lane $1=$ negative control, Lanes 5, 6, and $10=b l a_{\mathrm{TEM}}$ gene fragments, Lanes 2 , 9 , and $12=b l a_{T E M}, b l a_{S H V}, b l a_{C T X-M}$, and $b l a_{O X A}$ gene fragments, Lane $3=b l a_{C T X-M}$ gene fragments and Lanes $4,7,8,11$, and $13=b l a_{T E M}, b l a_{S H V}$, and $b l a_{C T X-M}$ gene fragments amplified from $E$. coli isolates.

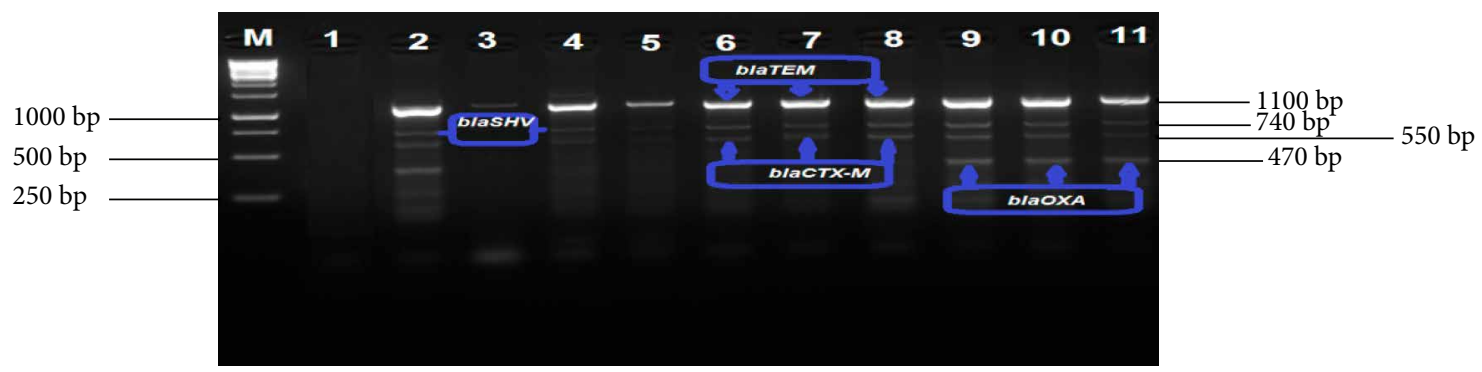

Figure 8: A $2 \%(\mathrm{w} / \mathrm{v})$ agarose gel image showing ESBL $\left[b l a_{T E M}(1100 \mathrm{bp}), b l a_{S H V}(740 \mathrm{bp}), b l a_{C T X-M}(550 \mathrm{bp})\right.$ and $\left.b l a_{O X A}(470 \mathrm{bp})\right]$ gene fragments amplified from $K$. pneumoniae isolates. Lane $\mathrm{M}=1 \mathrm{~kb}$ DNA Ladder (O'GeneRuler), Lane $1=$ negative control, Lanes $2,9,10$, and $11=b l a_{T E M}$, $b l a_{S H V}, b l a_{C T X-M}$, and $b l a_{O X A}$ gene fragments, Lane $3=b l a_{T E M}$ gene fragments, Lanes $4,5,6,7$, and $8=b l a_{T E M}, b l a_{S H V}$ and $b l a_{C T X-M}$ gene fragments.

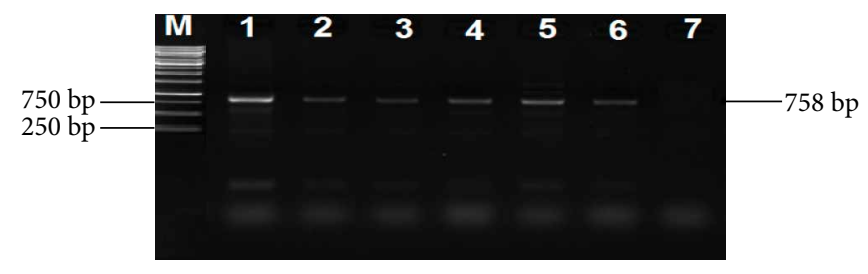

FIGURE 9: A 2\% (w/v) agarose gel image showing $b l a_{C M Y-2}$ ESBL gene fragments amplified from $E$. coli isolates. Lane $\mathrm{M}=1 \mathrm{~kb}$ DNA Ladder. Lanes $1-6=b l a_{C M Y-2}$ gene fragments amplified from $E$. coli isolates and Lane $7=$ negative control.

for E. coli O157 strains in the North-West province of South Africa [17, 34].

Antibiotic resistance is currently a very serious problem that has received great attention from the larger scientific community due to its impact on both hospital as well as community settings [35]. This, therefore, implies that rapid detection of resistant determinants in bacteria within diagnostic laboratories and knowledge of the antibiotic resistant profiles of circulating strains is very essential for the judicious recognition of the impact of these organisms to humans in a given geographical location. Within the family Enterobacteriaceae, the production of extended spectrum beta-lactamases is currently on the increase particularly among E. coli and K. pneumoniae species $[35,36]$, and these enzymes mediate in cellular processes that impede on treatment of infections caused by these pathogens $[35,37]$.

In the present study, large proportions (54.5-100\%) of the isolates were resistant to Amoxicillin. In addition, 33.3-100\% of the isolates were also resistant to Piperacillin while 14.3$100 \%$ were resistant to Cefotaxime. Similar observations had been reported $[14,38]$. Furthermore, significantly larger proportions (16.7-90\% and 16.7-66.7\%) were frequently resistant to Cephalothin and Ceftazidime, respectively. Isolates from Brits and Stella were most often resistant to these drugs when compared to those from the other sampling sites. Previous findings as well as antimicrobial usage surveillance data in the study area revealed that the frequent utilization of beta-lactam antibiotics in the treatment of bacterial infections continue to be the prominent cause of high levels of beta-lactam resistance among Gram-negative bacteria [6]. In addition, the potential of ESBL-producing organisms to resistant destruction when exposed to beta-lactam antibiotics is also enhanced by frequent mutations that occur in the gene sequences encoding for beta-lactamases [6, 7]. This could account for the high levels of resistance observed against Amoxicillin since this antimicrobial agent is extensively used as the preferred drug in the treatment of bacterial infections in both veterinary and human medicine [14]. Cluster analysis of antibiotic growth inhibition zone diameter data revealed that subcluster $1 \mathrm{~A}$ was a mixed cluster that contained isolates from all the different sample sites. These data indicate that the antibiotypes of isolates within subcluster $1 \mathrm{~A}$ were similar and this might be due to similar antimicrobial exposure histories. Changes in the antimicrobial phenotypes may be associated with environmental factors or the acquisition of plasmids. However, the utilization of an antibiotic phenotypic typing method in which isolates are clustered based on raw antibiotic growth inhibition diameter data was efficient in the typing and nosocomial 


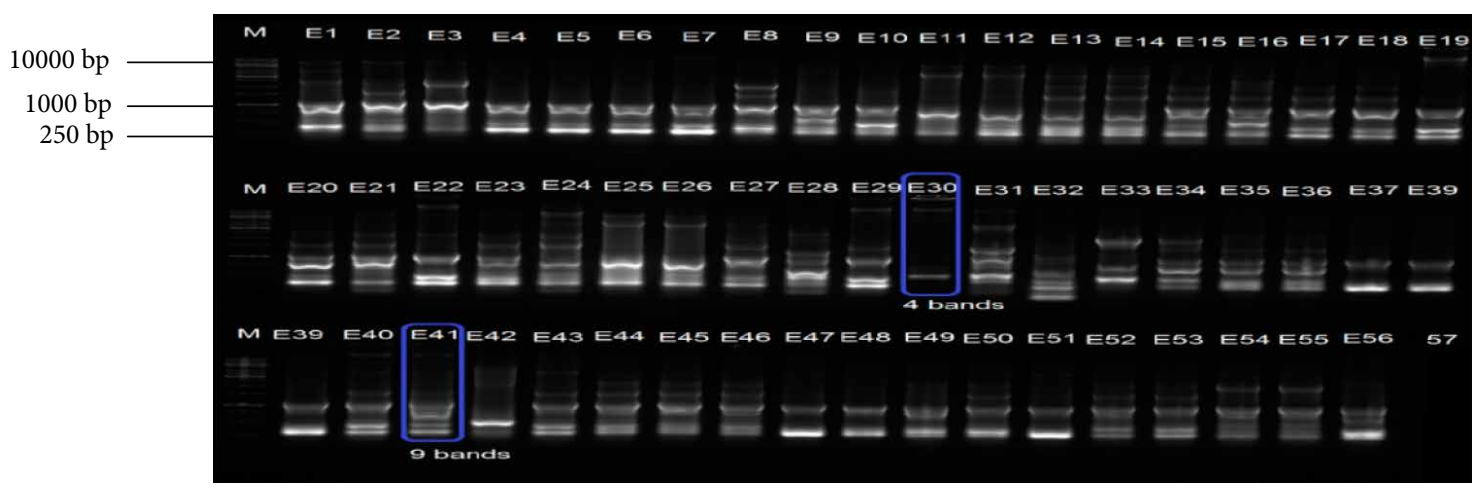

FIGURE 10: A 2\% (w/v) agarose gel image depicting Enterobacterial Repetitive Intergenic Consensus (ERIC) fingerprints of representative E. coli isolates. Lane $\mathrm{M}=1 \mathrm{~kb}$ DNA ladder, Lanes 1-32=ERIC fingerprints of $E$. coli isolates from beef samples, Lanes 33-56=ERIC fingerprints of $E$. coli isolates from cattle faeces and Lane $57=$ Negative control.

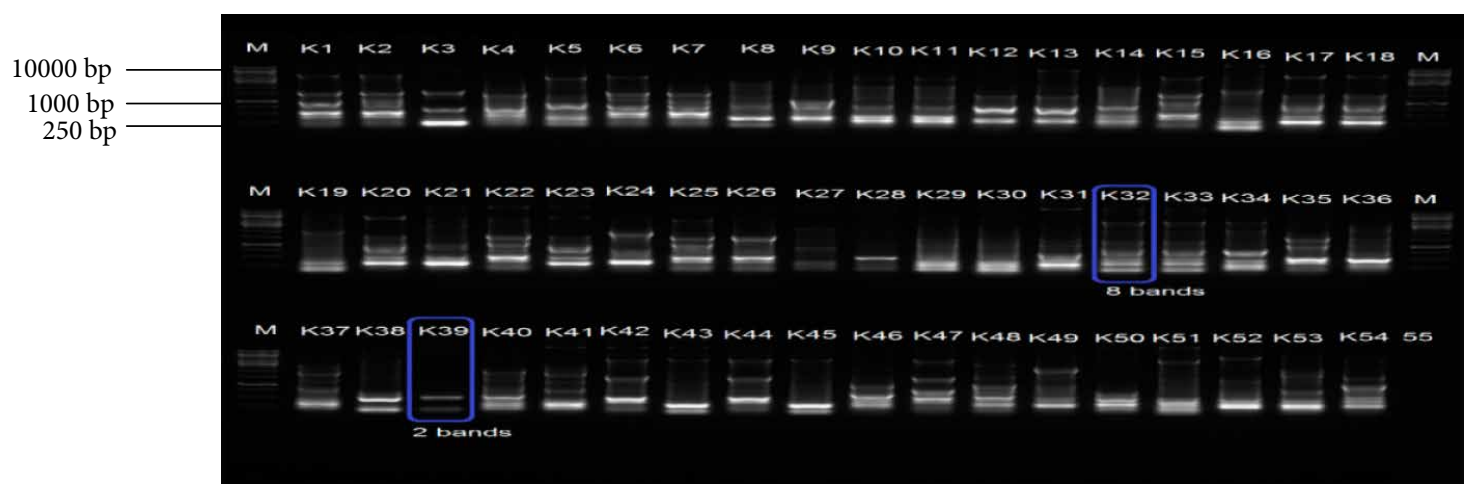

FIGURE 11: A 2\% (w/v) agarose gel image depicting Enterobacterial Repetitive Intergenic Consensus (ERIC) fingerprints of representative $K$. pneumoniae isolates. Lane $\mathrm{M}=1 \mathrm{~kb}$ DNA ladder, Lanes $1-54=$ ERIC fingerprints of $K$. pneumoniae isolates from beef samples and Lanes $55=$ Negative control.

infection surveillance of Methicillin Resistant Staphylococcus aureus [39]. The natural hosts of E. coli and K. pneumoniae species are ruminant animals especially cattle indicating these antimicrobial resistance pathogens can easily contaminate food products and be transmitted to humans. Therefore, an investigation of the ESBL profiles among E. coli and K. pneumoniae strains in animals is of paramount importance, and data generated may assist in limiting cross-contamination [17].

A further objective of the study was to screen E. coli and $K$. pneumoniae isolates for ESBL antibiotic resistance gene determinants. Despite the fact that ESBL resistance genes have most frequently been detected among $E$. coli and K. pneumoniae isolated from humans, clinical care and hospital facilities, a number of studies have also reported that ESBL resistance genes are harboured by E. coli and $K$. pneumoniae strains from food-producing animals, meat products as well as vegetables $[9,11,14,38,40-44]$. In most studies, ESBL genes (blaCXT-M, blaTEM, blaSHV, blaOXA and blaCMY) were the most frequently detected resistant determinants in E. coli, K. pneumoniae and Salmonella species $[6,14,37]$. ESBL isolates that possess these resistant determinants particularly blaCXT-M may pose severe public health complications to humans if consumption in contaminated food products $[11,14,40-44]$.
In the present study, large proportions $(53.1 \%)$ of the isolates possessed ESBL genes and the blaCTX-M, blaSHV and blaTEM genes most frequently detected in E. coli than in $K$. pneumoniae isolates. These results are in accordance with the findings of a previous study conducted in the Eastern Cape Province, South Africa as well as in India [14, 41-44]. Of great concern ESBL gene determinants detected in the present study was higher than those of a similar study previously conducted in Nigeria [38]. It is hereby suggested that the proportion of ESBL resistant gene determinants reported among bacteria isolates may be dependent on differences in geographical locations, sensitivity of the methods used to either isolate bacteria or detect resistance genes as well as the source and nature of specimens analysed.

The last objective of this study was to determine the genetic relatedness of ESBL-producing $E$. coli and $K$. pneumoniae isolates using ERIC PCR analysis. ERIC PCR analysis was usually employed to amplify various regions of DNA flanked by conserved sequences in order to generate isolate specific genetic fingerprints [28]. ERIC typing results revealed that isolates from different sources and/or locations shared similar genetic fingerprinting patterns and in particular those from cattle faeces and beef samples. The great similarities in genetic fingerprints indicate that the isolates may have originated from a common ancestral strain. ERIC-PCR band patterns of $K$. 
pneumoniae isolates from beef samples were very similar despite the differences in their sampling stations and this was in accordance with a previous report [45]. The findings of several studies have revealed that ERIC fingerprinting is a reliable tool for discriminating among isolates from different sources and hence considered to be a powerful tool for surveillance and control of antibiotic resistant bacteria [28, 46, 47]; these data indicate the need to improve on farm management techniques as well as standard operational procedures in abattoirs. In addition, contamination of raw beef with these multi-drug resistant pathogens may have also occurred at sale points and this, therefore, amplifies the need to enforce proper hygiene practices in supermarkets.

\section{Conclusion}

To the best of our knowledge, this is the first study to report the occurrence of ESBL producing E. coli and K. pneumoniae in cattle faeces and their associate food products (beef) in the study area. Large proportions (66.7-100\%) of multidrug resistant isolates were present in the samples and these isolated clustered together based on their antibiotic inhibition zone diameter data suggesting a very close link in antibiotic exposure histories. Large proportions of these E. coli and K. pneumoniae isolates displayed ESBL phenotypic resistance traits, while $53.1 \%$ harboured ESBL gene determinants. The blaTEM, blaSHV and blaCTX-M genes were detected in E. coli isolates (85.5\%, 69.6\%, and 58\%, respectively) while blaCTX-M and blaOXA were detected in K. pneumoniae (40\% and $42.9 \%$, respectively). In conclusion these findings indicate that, tracking and monitoring the spread of ESBL producing strains in food producing animals and beef at farms and sales points are urgently needed to improve public health in South Africa.

\section{Limitations and Suggestion}

There are several members of Enterobacteriaceae living in the intestines of animals and isolated from their faeces. However, in the study focus was directed at isolating E. coli and Klebsiella pneumoniae and this was a limitation for the study. Another limitation of the study was that cattle faeces were collected from one district (Mafikeng), whereas beef samples were collected from all the four districts of the North-West province. Thus, the data obtained from cattle faeces might not completely reflect the actual prevalence of ESBL producing organisms in cattle. Despite this, it is suggested that further studies should be carried out to determine the linkage of ESBL producers in animals and human and to address factors that contributes to the successful dissemination of ESBL producing strains to human.

\section{Data Availability}

No access to data on the antimicrobials used in the investigated farms; unavailability or scarcity of data from meat wholesale suppliers and the Department of Agriculture, Forestry and Fisheries of South Africa.

\section{Conflicts of Interest}

The authors declare that there have no conflicts of interest regarding the publication of this paper.

\section{Author's Contributions}

Kotsoana Peter Montso, Sicelo Beauty Dlaminia, Ajay Kumar, and Collins Njie Ateba are contributed equally to this work.

\section{Funding}

This study was funded and supported by the National Research Foundation (NRF) [Grant No: 90174] and Postgraduate bursary of the North-West University, Mafikeng Campus, South Africa.

\section{Supplementary Materials}

Figure S1: a flow chart illustrating sample collection and bacterial characterization. (Supplementary Materials)

\section{References}

[1] M. Saravanan, B. Ramachandran, and H. Barabadi, "The prevalence and drug resistance pattern of extended spectrum $\beta$-lactamases (ESBLs) producing Enterobacteriaceae in Africa," Microbial Pathogenesis, vol. 114, pp. 180-192, 2018.

[2] D. L. Paterson and R. A. Bonomo, "Extended-spectrum $\beta$-lactamases: a clinical update," Clinical Microbiology Reviews, vol. 18, no. 4, pp. 657-686, 2005.

[3] S. N. Seiffert, M. Hilty, V. Perreten, and A. Endimiani, "Extendedspectrum cephalosporin-resistant gram-negative organisms in livestock: an emerging problem for human health?" Drug Resistance Updates, vol. 16, no. 1-2, pp. 22-45, 2013.

[4] X. Zeng and J. Lin, "Beta-lactamase induction and cell wall metabolism in gram-negative bacteria," Frontiers in Microbiology, vol. 4, p. 128, 2013.

[5] P. Da Costa, L. Loureiro, and A. Matos, "Transfer of multidrugresistant bacteria between intermingled ecological niches: the interface between humans, animals and the environment," International Journal of Environmental Research and Public Health, vol. 10, no. 1, pp. 278-294, 2013.

[6] J. D. Pitout, P. Nordmann, K. B. Laupland, and L. Poirel, "Emergence of Enterobacteriaceae producing extendedspectrum $\beta$-lactamases (ESBLs) in the community," Journal of Antimicrobial Chemotherapy, vol. 56, no. 1, pp. 52-59, 2005.

[7] J. D. Pitout and K. B. Laupland, "Extended-spectrum $\beta$-lactamase-producing Enterobacteriaceae: an emerging public-health concern," The Lancet Infectious Diseases, vol. 8, no. 3, pp. 159-166, 2008.

[8] S. Rath, D. Dubey, M. C. Sahu, and R. N. Padhy, "Surveillance of ESBL producing multidrug resistant Escherichia coli in a teaching hospital in India," Asian Pacific Journal of Tropical Disease, vol. 4, no. 2, pp. 140-149, 2014.

[9] A. Carattoli, "Animal reservoirs for extended spectrum $\beta$-lactamase producers," Clinical Microbiology and Infection, vol. 14, pp. 117-123, 2008. 
[10] D. Meunier, E. Jouy, C. Lazizzera, M. Kobisch, and J. Y. Madec, "CTX-M-1-and CTX-M-15-type $\beta$-lactamases in clinical Escherichia coli isolates recovered from food-producing animals in France," International Journal of Antimicrobial Agents, vol. 28, no. 5, pp. 402-407, 2006.

[11] D. Kar, S. Bandyopadhyay, D. Bhattacharyya et al., "Molecular and phylogenetic characterization of multidrug resistant extended spectrum beta-lactamase producing Escherichia coli isolated from poultry and cattle in Odisha, India," Infection, Genetics and Evolution, vol. 29, pp. 82-90, 2015.

[12] L. B. Said, A. Jouini, N. Klibi et al., "Detection of extendedspectrum beta-lactamase (ESBL)-producing Enterobacteriaceae in vegetables, soil and water of the farm environment in Tunisia," International Journal of Food Microbiology, vol. 203, pp. 86-92, 2015.

[13] M. Haenni, P. Châtre, V. Métayer et al., "Comparative prevalence and characterization of ESBL-producing Enterobacteriaceae in dominant versus subdominant enteric flora in veal calves at slaughterhouse, France," Veterinary Microbiology, vol. 171, no. 3-4, pp. 321-327, 2014.

[14] B. C. Iweriebor, C. J. Iwu, L. C. Obi, U. U. Nwodo, and A. I. Okoh, "Multiple antibiotic resistances among Shiga toxin producing Escherichia coli O157 in feces of dairy cattle farms in Eastern Cape of South Africa," BMC Microbiology, vol. 15, no. 1, Article ID 213, 2015.

[15] “Provincial Economies, 2004," 2018, http://www.nwpg.gov.za/ Agriculture.htm.

[16] P. Boerlin, A. Wissing, F. M. Aarestrup, J. Frey, and J. Nicolet, "Antimicrobial growth promoter ban and resistance to macrolides and vancomycin in enterococci from pigs," Journal of Clinical Microbiology, vol. 39, no. 11, pp. 4193-4195, 2001.

[17] C. N. Ateba and M. Mbewe, "Detection of Escherichia coli O157: $\mathrm{H} 7$ virulence genes in isolates from beef, pork, water, human and animal species in the northwest province, South Africa: public health implications," Research in Microbiology, vol. 162, no. 3, pp. 240-248, 2011.

[18] R. Cruickshank, J. P. Duguid, B. R. Marmion, and R. H. Swain, Medical Microbiology, Churchill-Living Stone, London, UK, 12th edition, 1975.

[19] A. B. Forbes and A. S. Weissfeld, Bailey and Scott's Diagnostic Microbiology, Mosby, St Louis, MO, 10th edition, 1998.

[20] K. Sturød, U. R. Dahle, E. S. Berg, M. Steinbakk, and A. L. Wester, "Evaluation of the ability of four ESBL-screening media to detect ESBL-producing Salmonella and Shigella," BMC Microbiology, vol. 14, no. 1, Article ID 217, 2014.

[21] E. Korzeniewska and M. Harnisz, "Beta-lactamaseproducing Enterobacteriaceae in hospital effluents," Journal of Environmental Management, vol. 123, pp. 1-7, 2013.

[22] E. M. Anastasi, B. Matthews, A. Gundogdu et al., "Prevalence and persistence of Escherichia coli strains with uropathogenic virulence characteristics in sewage treatment plants," Applied Environmental Microbiology, vol. 76, no. 17, pp. 5882-5886, 2010.

[23] D. Anbazhagan, W. S. Mui, M. Mansor, G. O. S. Yan, M. Y. Yusof, and S. D. Sekaran, "Development of conventional and real-time multiplex PCR assays for the detection of nosocomial pathogens," Brazilian Journal of Microbiology, vol. 42, no. 2, pp. 448-458, 2011.

[24] A. W. Bauer, W. M. M. Kirby, J. C. Sherris, and M. Turck, "Antibiotic susceptibility testing by a standardized single disk method," American Journal of Clinical Pathology, vol. 45, no. 4_ts, pp. 493-496, 1966.
[25] "Performance standards for antimicrobial susceptibility testing; twenty-fourth information supplement," Clinical and Laboratory Standards Institute Antimicrobial Susceptibility Testing, vol. M100-S24, pp. 230-341, 2014.

[26] H. Hasman, D. Mevius, K. Veldman, I. Olesen, and F. M. Aarestrup, “ $\beta$-Lactamases among extended-spectrum $\beta$-lactamase (ESBL)-resistant Salmonella from poultry, poultry products and human patients in The Netherlands," Journal of Antimicrobial Chemotherapy, vol. 56, no. 1, pp. 115-121, 2005.

[27] S. M. Al-Mayahie, "Phenotypic and genotypic comparison of ESBL production by vaginal Escherichia coli isolates from pregnant and non-pregnant women," Annals of Clinical Microbiology and Antimicrobials, vol. 12, no. 1, pp. 1-7, 2013.

[28] C. Ateba and M. Mbewe, "Genotypic characterization of Escherichia coli O157: H7 isolates from different sources in the north-west province, South Africa, using Enterobacterial Repetitive Intergenic Consensus PCR analysis," International Journal of Molecular Sciences, vol. 15, no. 6, pp. 9735-9747, 2014.

[29] L. Valentin, H. Sharp, K. Hille et al., "Subgrouping of ESBLproducing Escherichia coli from animal and human sources: an approach to quantify the distribution of ESBL types between different reservoirs," International Journal of Medical Microbiology, vol. 304, no. 7, pp. 805-816, 2014.

[30] L. Gao, Y. Tan, X. Zhang et al., "Emissions of Escherichia coli carrying extended-spectrum $\beta$-lactamase resistance from pig farms to the surrounding environment," International Journal of Environmental Research and Public Health, vol. 12, no. 4, pp. 4203-4213, 2015.

[31] A. Smet, A. Martel, D. Persoons et al., "Broad-spectrum $\beta$-lactamases among Enterobacteriaceae of animal origin: molecular aspects, mobility and impact on public health," FEMS Microbiology Reviews, vol. 34, no. 3, pp. 295-316, 2010.

[32] N. Geser, R. Stephan, and H. Hächler, "Occurrence and characteristics of extended-spectrum $\beta$-lactamase (ESBL) producing Enterobacteriaceae in food producing animals, minced meat and raw milk," BMC Veterinary Research, vol. 8, no. 1, Article ID 21, 2012.

[33] A. Schmid, S. Hörmansdorfer, U. Messelhäusser, A. Käsbohrer, C. Sauter-Louis, and R. Mansfeld, "Prevalence of extendedspectrum $\beta$-lactamase-producing Escherichia coli on Bavarian dairy and beef cattle farms," Applied Environmental Microbiology, vol. 79, no. 9, pp. 3027-3032, 2013.

[34] C. N. Ateba and C. C. Bezuidenhout, "Characterisation of Escherichia coli $\mathrm{O} 157$ strains from humans, cattle and pigs in the North-West Province, South Africa," International Journal of Food Microbiology, vol. 128, no. 2, pp. 181-188, 2008.

[35] S. Shaikh, J. Fatima, S. Shakil, S. M. D. Rizvi, and M. A. Kamal, "Antibiotic resistance and extended spectrum beta-lactamases: Types, epidemiology and treatment," Saudi Journal of Biological Sciences, vol. 22, no. 1, pp. 90-101, 2015.

[36] I. Roca, M. Akova, F. Baquero et al., "The global threat of antimicrobial resistance: science for intervention," New Microbes and New Infections, vol. 6, pp. 22-29, 2015.

[37] P. A. Bradford, "Extended-spectrum $\beta$-lactamases in the 21st century: characterization, epidemiology, and detection of this important resistance threat," Clinical Microbiology Reviews, vol. 14, no. 4, pp. 933-951, 2001.

[38] O. A. Olowe, O. Adewumi, G. Odewale, O. Ojurongbe, and O. J. Adefioye, "Phenotypic and molecular characterisation of extended-spectrum beta-lactamase producing Escherichia 
coli obtained from animal fecal samples in Ado Ekiti, Nigeria," Journal of Environmental and Public Health, vol. 2015, pp. 1-7, 2015.

[39] D. S. Blanc, C. Petignat, P. Moreillon, A. Wenger, J. Bille, and P. Francioli, "Quantitative antibiogram as a typing method for the prospective epidemiological surveillance and control of MRSA comparison with molecular typing," Infection Control and Hospital Epidemiology, vol. 17, no. 10, pp. 654-659, 1996.

[40] H. S. Kim, J. W. Chon, Y. J. Kim, D. H. Kim, M. S. Kim, and K. H. Seo, "Prevalence and characterization of extendedspectrum- $\beta$-lactamase-producing Escherichia coli and Klebsiella pneumoniae in ready-to-eat vegetables," International Journal of Food Microbiology, vol. 207, pp. 83-86, 2015.

[41] M. S. Murugan, D. K. Sinha, O. V. Kumar et al., "Epidemiology of carbapenem-resistant Escherichia coli and first report of bla $a_{V I M}$ carbapenemases gene in calves from India," Epidemiology and Infection, vol. 147, 2019.

[42] K. R. Nirupama, V. K. Or, B. S. Pruthvishree et al., "Molecular characterisation of $b l a_{O X A-48}$ carbapenemase-, extendedspectrum $\beta$-lactamase- and Shiga toxin-producing Escherichia coli isolated from farm piglets in India," Journal of Global Antimicrobial Resistance, vol. 13, pp. 201-205, 2018.

[43] B. S. Pruthvishree, O. R. Vinodh Kumar, D. K. Sinha et al., "Spatial molecular epidemiology of carbapenem-resistant and New Delhi metallo beta-lactamase $\left(b l a_{\mathrm{NDM}}\right)$-producing Escherichia coli in the piglets of organized farms in India," Journal of Applied Microbiology, vol. 122, no. 6, pp. 1537-1546, 2017.

[44] O. R. Vinodh Kumar, B. R. Singh, D. K. Sinha et al., "Risk factor analysis, antimicrobial resistance and pathotyping of Escherichia coli associated with pre- and post-weaning piglet diarrhoea in organised farms, India," Epidemiology and Infection, vol. 147, 2019.

[45] A. B. Cabral, R. D. C. D. A. Melo, M. A. V. Maciel, and A. C. S. Lopes, "Multidrug resistance genes, including blaKPC and blaCTX-M-2, among Klebsiella pneumoniae isolated in Recife, Brazil," Journal of the Brazilian Society of Tropical Medicine, vol. 45, no. 5, pp. 572-578, 2012.

[46] G. Nath, P. Maurya, and A. K. Gulati, "ERIC PCR and RAPD based fingerprinting of Salmonella Typhi strains isolated over a period of two decades," Infection, Genetics and Evolution, vol. 10, no. 4, pp. 530-536, 2010.

[47] B. Bakhshi, N. Afshari, and F. Fallah, "Enterobacterial Repetitive Intergenic Consensus (ERIC)-PCR analysis as a reliable evidence for suspected Shigella spp. outbreaks," Brazilian Journal of Microbiology, vol. 49, no. 3, pp. 529-533, 2018. 


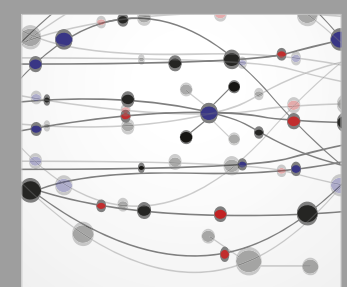

The Scientific World Journal
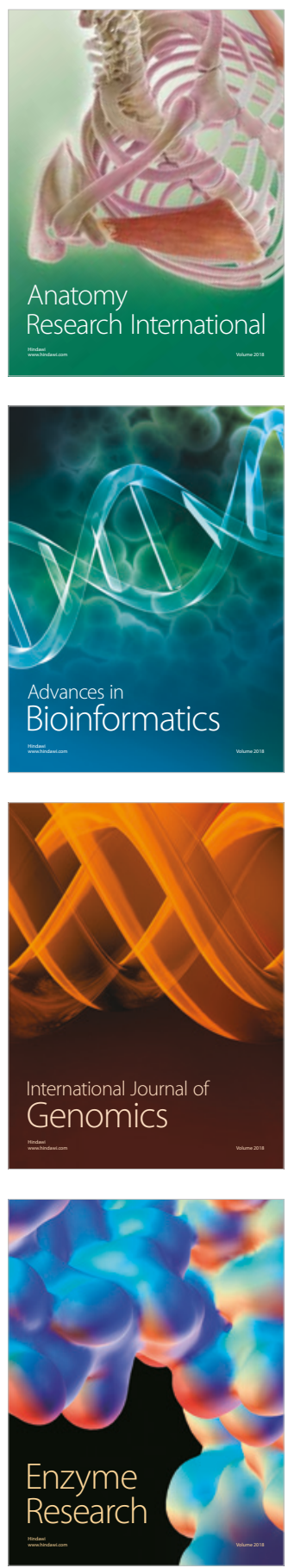
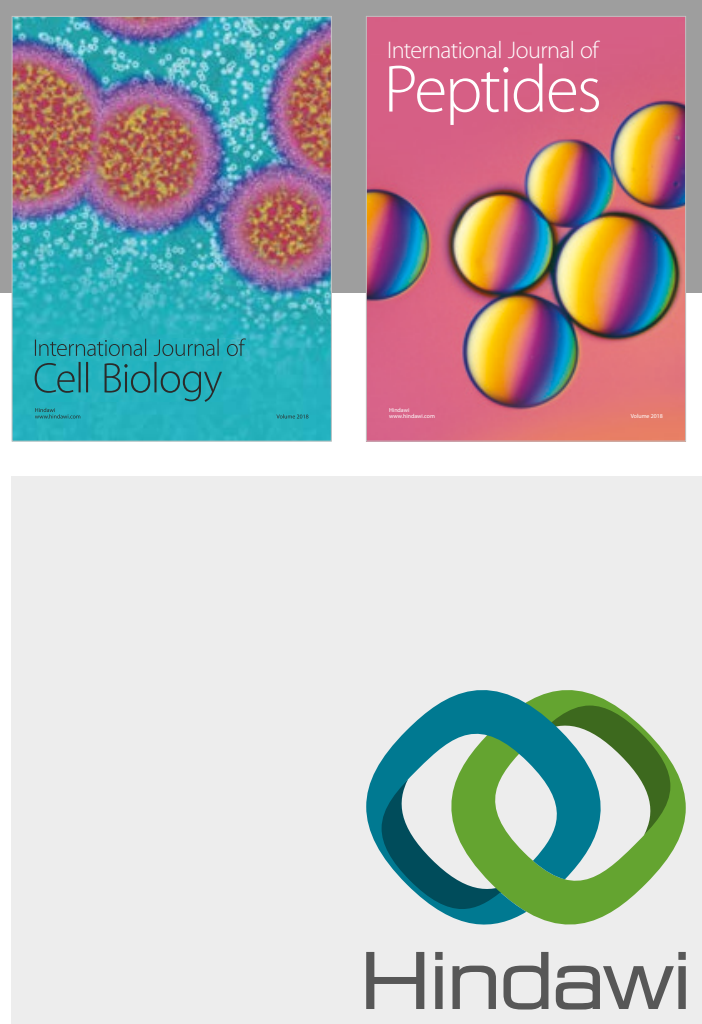

Submit your manuscripts at

www.hindawi.com
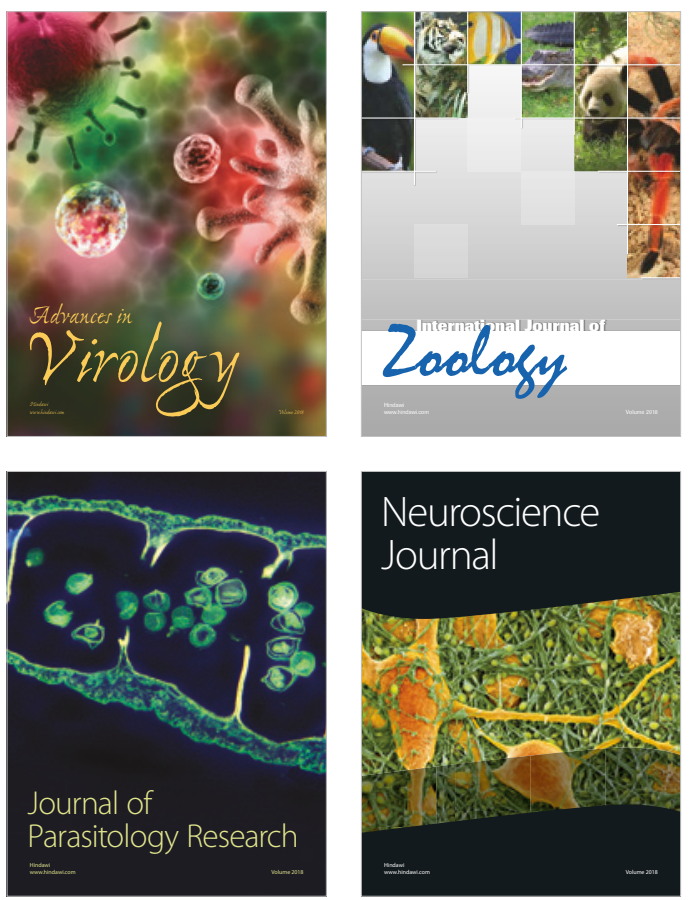
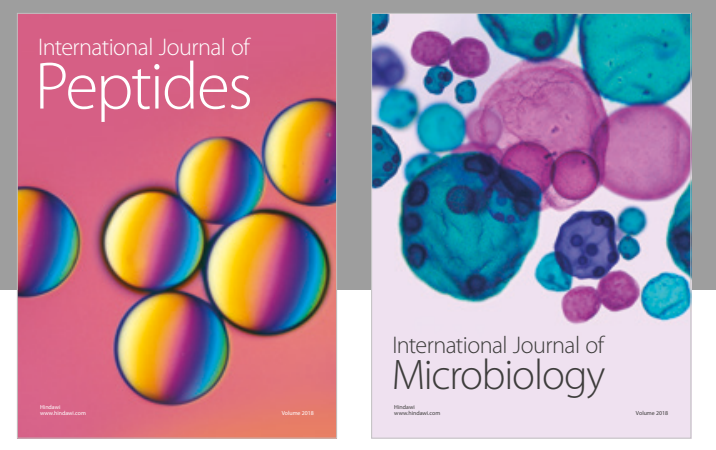

nternational Journal of Microbiology
Journal of
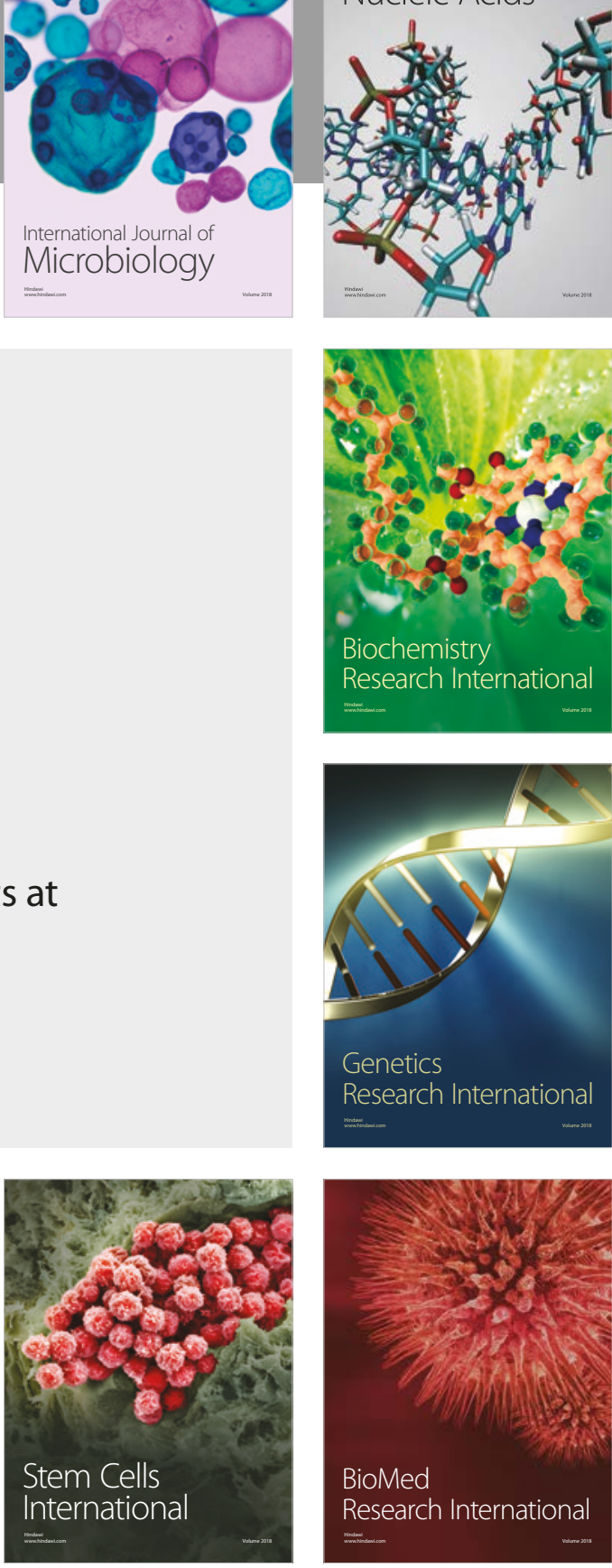
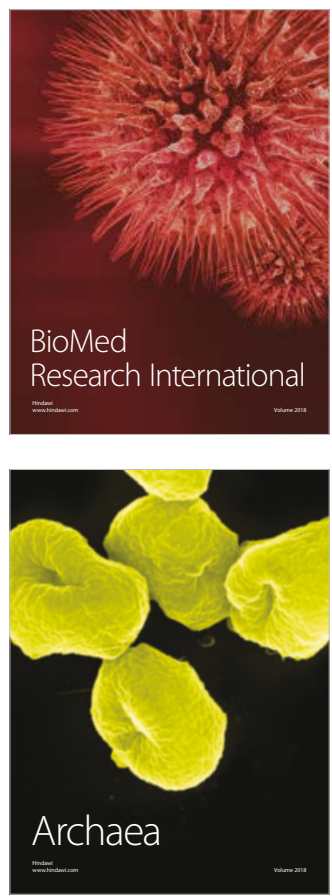